\title{
Researching college students' conceptions of mathematics in calculus
}

\author{
Tung-Shyan Chen * \\ National Chin-Yi University of Technology, Taichung, Taiwan
}

\section{Key Words \\ Calculus \\ Conceptions of mathematics \\ Mathematical culture}

Received: 31 July 2016

Accepted: 25 September 2016

Published: 19 December 2016

\begin{abstract}
Calculus is important in today's mathematics. This paper investigated Taiwanese college students' conceptions of mathematics by permeating mathematical culture in calculus. Forty-three college students who had a major in management participated in this study. A qualitative belief questionnaire, students' in-class reports, and achievement tests were sources used to observe the development of students' conceptions. In the beginning, there were $65.12 \%$ of students espousing narrow views, whereas it decreased to $34.88 \%$ at the end. Research shows that students with broad conceptions from 15 students increased to 28 students (increased to $86.67 \%$ ). The research concludes that permeating mathematical culture into calculus teaching will improve students' conceptions of mathematics towards a broader perspective. Based on the findings, we can design a curriculum to stimulate students towards the broader conceptions of mathematics in calculus. We suggest that permeating mathematical culture in calculus teaching is appropriate for encouraging students to hold broader conceptions.
\end{abstract}

(C)2016 The Author(s). Published by TAF Publishing.

\section{INTRODUCTION AND BACKGROUND}

Studying calculus is important because it is the base for learning at university level. Calculus is also necessary for the success in several subjects at the undergraduate level (Biza and Theodossios, 2007; Siti Fatimah et al. 2015). Students' conceptions of mathematics have a great effect on calculus learning. Research at the school level indicates that the learners' previous experiences influence the quality of their approaches to learning, attitudes to and outcomes in learning mathematics (Crawford, 1990; Crawford et al. 1994; Ülkü Yildiz, and Gökhan, 2015).

Taiwanese students perform well in international studies of mathematics achievement (e.g., the Program for International Student Assessment (PISA) and Trends in International Mathematics and Science Study (TIMSS)), but their excellent achievements are not accompanied by correspondingly positive attitude towards mathematics. Difficult, boring, abstract, inscrutable, dread and tedious are termed "negative emotions" because they make students lose confidence and feel miserable about mathematics (Chen, 2014).

Students' conceptions of the nature of mathematics have a great effect on mathematics learning and mathematics plays an important role in many careers. Petocz et al. (2007) described conceptions of mathematics ranging from narrow views to broad views. Petocz et al. (2007) actually defined a very low level "Number" category: mathematics is a combination of numbers and calculations. Here, mathematics is just a computing subject. "Components": mathematics is viewed as a problem-solving tool. "Modelling": mathematics is used to describe and explain the real world. "A bstract": mathematics is built based on log-

\footnotetext{
${ }^{*}$ Corresponding author: Tung-Shyan Chen

${ }^{\dagger}$ Email: chentsn@gmail.com
} 
ical system to solve complex problems. The broadest view of mathematics was labelled "Life": students view mathematics as an approach to life and a way of thinking, and make a strong personal connection between mathematics and their own lives. Mathematics is the language of nature.

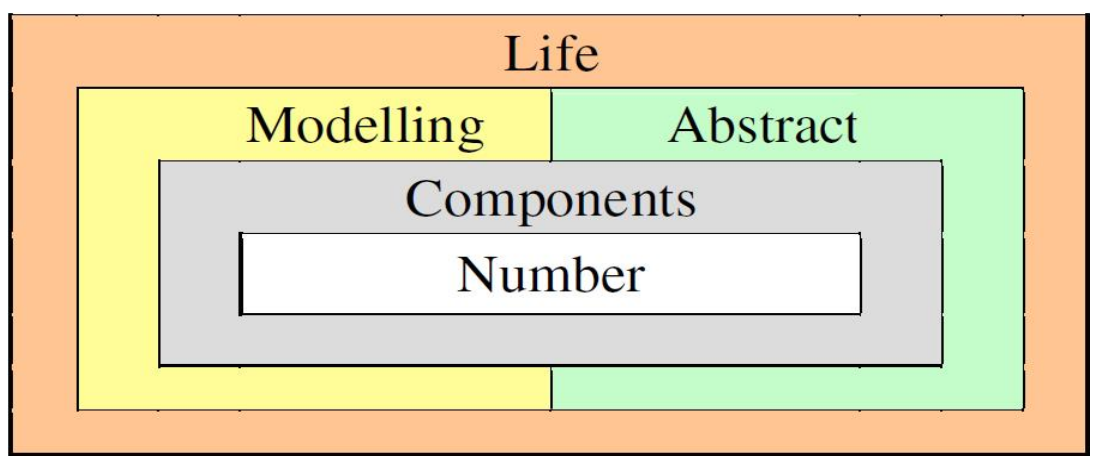

FIGURE 1 . Relationship between conceptions (Petocz et al. 2007)

In this paper, we denote "narrow" conceptions of mathematics by including labelled Number and Components. We define "broad" views by containing labelled Modelling, Abstract, and Life. Based on the teaching and researching, this study aims at investigated Taiwanese college students' conceptions of mathematics and to analyze if there are differences in conceptions by permeating mathematical culture in calculus. The rest of the paper is organized as follows: In the second section, we describe the methodology of the study. Then we describe in detail the results of the study in the third section and conclude our work in the last section.

\section{METHODOLOGY}

\section{Participants}

In this study, 43 Taiwanese college students (21 females and 22 males) having major in management were involved. Technological university students in Taiwan are generally equipped with the expertise in practical skills that fulfill industrial and business demands. Most of these first-year students recently graduated from vocational high schools.

\section{Design}

Calculus, a core course preparing the student for advanced mathematics-related courses, is required for all. The experiment was conducted during two consecutive semesters, the fall of 2015 and the spring of 2016. In this study, we used a qualitative belief questionnaire, students' in-class reports, and the achievement tests in order to survey the development of students' views of mathematics. The qualitative belief questionnaire included the important question: What do you think mathematics is?

\section{Mathematical Culture}

Mathematics is not only a science but also a culture that is "mathematical culture": mathematics is not only some knowledge but also a literacy that is "mathematical literacy". Burton $(2009,157)$ identified "mathematical culture as the set of socio-political attitudes, values and behaviors that, in situations of communication around mathematics, shape how mathematics practitioners experience mathematics". In 2013 International Symposium on Mathematical Culture and Education, Liu presented mathematical culture in an inter- 
Mathematical culture $=\int_{0}^{\infty} \int_{\text {past }}^{\text {now }} \int_{\text {east }}^{\text {west }} K(m, t, u) d m d t d u$

$K$ : knowledge, $m:$ mathematician, $t:$ time, $u:$ universe.

Li and Huang (2011) described that "the integration of mathematical culture into mathematics teaching is of great value in mathematical education, because it helps to stimulate students' interests in learning, to form their mathematical thinking, to enhance their confidence in studying and their courage to overcome difficulties, to serve as an educational guide for teachers' choice of teaching methods, and to reveal the humanist aspect of mathematical knowledge" (Li and He, 2011, 520).

We demonstrated the context of mathematical culture by showing the history of mathematics. Lockhart (2009) complained about the fact that conventional mathematics courses usually lack a historical perspective or thematic coherence. Liu (2003) proposed five reasons for comprising the history of mathematic. Besides textbook, we demonstrated the context of mathematical culture by showing the history of mathematics. Just like Kool's suggestion (Kool, 1992): "Do not talk about the history of mathematics in your classroom, but do it, use it!" We used historical problems and encouraged students to discover analogies between the old and the modern problems.

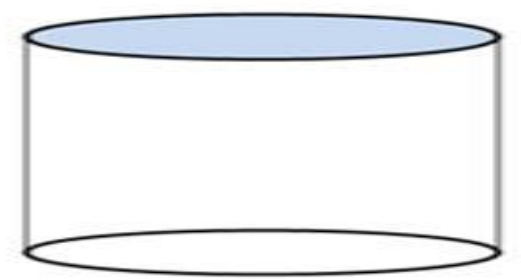

FIGURE 2 . Design a cylindrical can

We also designed some exercises that model the way mathematicians work in industry and academia in order to give students an idea of the way mathematics is used in their future professions. For instance, a standard can of soda holds $355 \mathrm{ml}$. Find the dimensions of a cylindrical can that will use the least amount of aluminum.

Some materials have been used in the paper (Chen and Po-Hung, 2015). Mathematical thinking is important as a way of learning mathematics. When we taught the slope of the tangent line to the graph of the function, we used figure 3 to emphasize the importance of mathematical thinking. In figure 3 , the upper triangle is made of four pieces. And the same pieces have been arranged in the triangle below. Where did the hole come from? That's because the slopes of medium and small triangles are different.

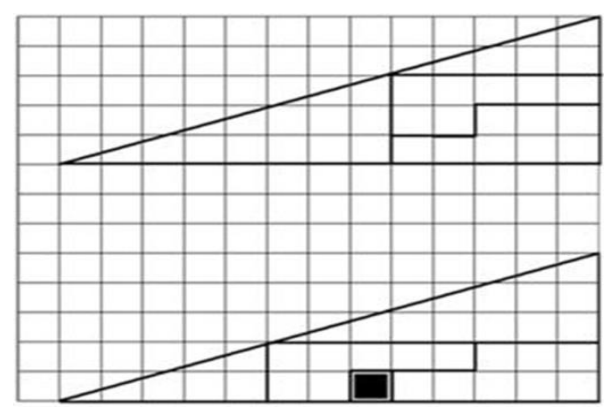

FIGURE 3 . Mathematical thinking: where did the hole come from? 
When teaching the topic "sequences", we showed mathematical beauty. The sunflower seed pattern contains many spirals (Figure 4). The number of spirals within a sunflower follows the Fibonacci sequence $\mathrm{F}_{n+2}=\mathrm{F}_{n}+\mathrm{F}_{n+1}, \mathrm{~F}_{0}=0, \mathrm{~F}_{1}=1$ or $0,1,1+1=2,1+2=3,2+3=5$, $3+5=8,5+8=13,8+13=21,13+21=34,21+34=55,34+55=89,55+89=144 \ldots$

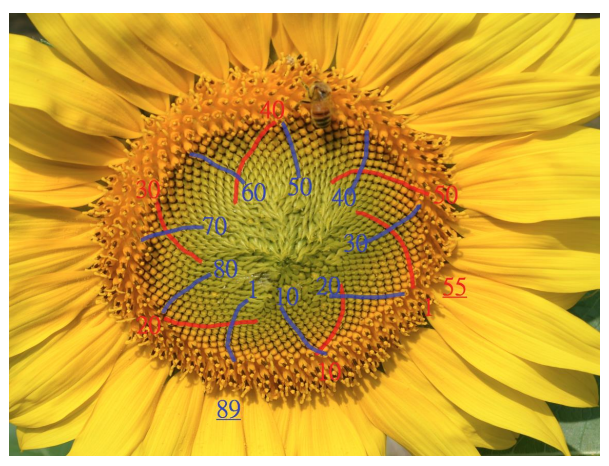

FIGURE 4 . Mathematical beauty: the sunflower seed pattern

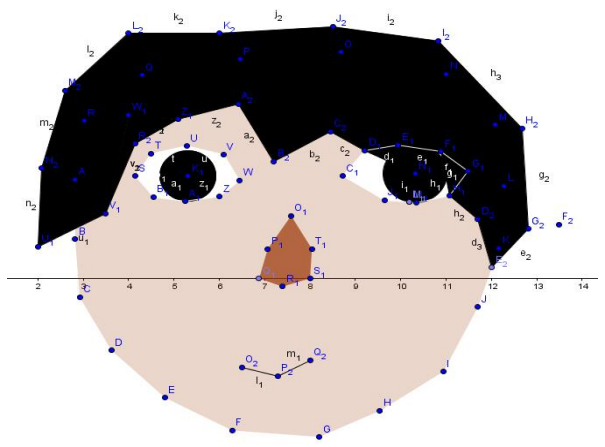

FIGURE 5. Student's homework: Use GeoGebra to draw a face

GeoGebra is a free and multi-platform dynamic mathematics application for those who study or work with arithmetic, geometry, algebra and calculus. Students were asked to use GeoGebra to study calculus. At the beginning, we designed learning tasks to download GeoGebra and use it to draw a face (Figure 5). Students can learn calculus from the visualization tool GeoGebra (Figure 6).

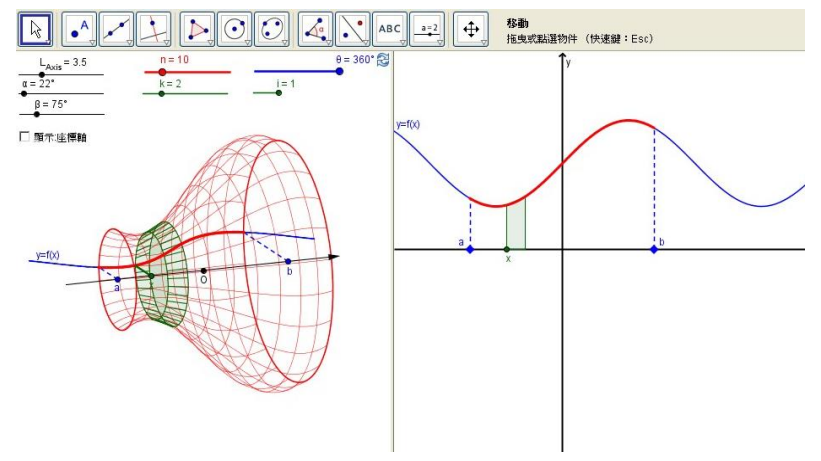

FIGURE 6. The visualization tool GeoGebra 
Conceptions of mathematics may be explored, motivated, and enlarged through literary art. Mathematical literature homework is designed for using the elements of mathematics to write literature. We also demonstrated the context of mathematical culture by showing mathematical methods, mathematical theorems, mathematical beauty, the philosophy of mathematics, mathematical literature, mathematical movie and mathematical extensions.

\section{RESULTS AND DISCUSSION}

Students' answers to the question "What is mathematics?" are really different. According to these answers, we divided students' conceptions of mathematics into two parts: broad conceptions and narrow conceptions of mathematics. Table 1 shows the changes in students' conceptions of mathematics from the beginning to the end. In the beginning, there were 28 students espousing narrow views, whereas it decreased to 15 at the end.

On the other hand, there were only 15 students with broad views at the outset and as high as 28 students articulating their broad conceptions of mathematics at the end. The upper triangular number 13 in Table 1 refers to the number of students who are towards broader conceptions of mathematics. The lower triangular number 0 in Table 1 means no students are towards narrower conceptions of mathematics. And the differences of students changing their conceptions are statistically significant (F-test $\mathrm{p}$-value $=$ $0.000<0.001$ ) through this study.

TABLE 1

Conceptions of mathematics

\begin{tabular}{lllll}
\hline \hline Stage & Conceptions of mathematics & At the end & & \\
\hline & & Narrow & Broad & Total \\
\hline In the beginning & Narrow & 15 & 13 & 28 \\
& Broad & 0 & 15 & 15 \\
& Total & 15 & 28 & 43 \\
\hline \hline
\end{tabular}

The diagonal numbers with underline indicate the number of students showing no changes in students' conceptions of mathematics. It is a pity that 15 students always possessed narrow conceptions of mathematics during this study. We should design better curriculum and individual learning tasks that encourage the next generation of students towards the broader conceptions. There are 15 students (6 females and 9 males) with broad conceptions through this study. The best student in calculus showed narrow view in the beginning and held broad conception at the end. In the beginning of questionnaire, she thought mathematics is a lot of numbers to calculate. She indicated the full range of conception of mathematics in this year, from "Number" to "Life".

\section{CONCLUSION AND RECOMMENDATIONS}

The results from this study had been positive by permeating mathematical culture in calculus. In the beginning, there were $65.12 \%$ of students espousing narrow views, whereas it decreased to $34.88 \%$ at the end. On the other hand, there were only $34.88 \%$ of students with broad views at the outset and $65.12 \%$ of students articulating their broad conceptions of mathematics at the end. No students were towards narrower conceptions of mathematics in this study. Research shows that the number of students with broad conceptions from 15 students increased to 28 students (increased to 86.67\%). The differences of students changing their conceptions of mathematics are statistically significant through this study.

Based on our findings, we can design curriculum to stimulate students towards the 
broader conceptions of mathematics in calculus. We suggest that permeating mathematical culture in calculus teaching is appropriate for encouraging students to hold broader conceptions.

\section{ACKNOWLEDGEMENTS}

The research presented in this paper has been funded by the Ministry of Science and Technology of Taiwan (MOST grant 103-2511-S-167-001-MY2).

\section{REFERENCES}

Biza, Irene, and Theodossios Zachariades. 2007. Using dynamic geometry to introduce calculus concepts: CalGeo and the case of the derivative. Paper presented at the Proceedings of the British Society for Research into Learning Mathe- matics 27, no. 2: 7-12.

Burton, Leone. 2009. The culture of mathematics and the mathematical culture. In University science and mathematics education in transition, ed. Ole Skovsmose Aalborg University, 7: 157-173, New York, NY: Springer.

DOI: $10.1007 / 978-0-387-09829-6 \_8$

Chen, T S. 2014. Improving college students' attitude towards mathematics through mathematical culture. Paper pre- $\quad$ sented at the 2nd IHPST Asian Regional Conference, Taipei, Taiwan.

Chen, Tung-Shyan and Po-Hung Liu. 2015. Researching engineering students' attitudes toward mathematics by permeating mathematical culture in calculus. International Journal of Arts \& Sciences 08, no. 03: 681-688.

Crawford, K, S. Gordon, J. Nicholas, and M. Prosser. 1994. Conceptions of mathematics and how it is learned: The perspec- tives of students entering university. Learning and Instruction 4, no. 4: 331-345.

DOI: $10.1016 / 0959-4752(94) 90005-1$

Crawford, K. 1990. School definitions of work: Their impact on the use of technology in mathematics education. Paper presented at the Proceedings of the Conference on the Political Dimensions of Mathematics Education. The Institute of Education, University of London, London, UK.

Kool, Marjolein. 1992. Dust clouds from the sixteenth century. The Mathematics Gazette 76, no. 475: 90-96.

DOI: $10.2307 / 3620381$

$\mathrm{Li}$, Yong and He Huang. 2011. Research on the value of mathematical culture in mathematics education based on data anal- ysis. In Advances in computer science, environment, ecoinformatics, and education, eds. Song Lin and Xiong Huang. Berlin, Germany, DE: Springer. DOI: 10.1007/978-3-642-23339-5_95

Liu, Po-Hung. 2003. Do teachers need to incorporate the history of mathematics in their teaching? Mathematics Teacher 96, no. 6: 416-421.

Lockhart, Paul. 2009. A mathematician's lament: how school cheats us out of our most fascinating and imaginative art form. New York, NY: Bellevue Literary Press.

Petocz, Peter, Anna Reid, Leigh N. Wo od, Geoff H. Smith, Glyn Mather, Ansie Harding, Johann Engelbrecht, Ken Houston, Joel

Hillel, Gillian Perrett. 2007. Undergraduate students' conceptions of mathematics: An international study. Interna- tional Journal of Science and Mathematics Education 5, no. 3: 439-459.

Siti Fatimah AZ, Norhafizah MS, Noryanti M, Rozieana K, and Hassan RG. (2015). A study of students' performance in calcu- lus and their attitudes toward the course using tripartite model. International Journal of Humanities, Arts and Social Sciences 1, no. 1: 30-35, 2015. DOI: 10.20469/ijhss.20005

Ülkü Yildiz, and Gökhan Kayili. 2015. Examining the effects of computer-assisted preschool educational activities on chil- dren's intuitive mathematical ability. Journal of Advances in Humanities and Social Sciences 1, no. 1: 1-8.

DOI: $10.20474 /$ jahss-1.1.1 